\title{
Beyond abundance and biomass: effects of marine protected areas on the demography of a highly exploited reef fish
}

\author{
Brett M. Taylor*, Jennifer L. McIlwain \\ University of Guam Marine Laboratory, Mangilao, Guam 96923
}

\begin{abstract}
The success of marine protected areas (MPAs) in facilitating recovery of over-exploited stocks has been well documented. Few studies, however, have explored the effects of MPAs on the demographic profiles of reef fish populations. We tested the assumption that areas closed to fishing for $>7 \mathrm{yr}$ accumulate older individuals of a heavily targeted species, Lethrinus harak. Our survey design included 2 protected sites and 2 comparative fished sites. Using an age-based lengthconversion method, a novel approach in tropical fisheries, otolith-derived demographic information was supplemented with underwater visual census data. This approach provided valuable insights into the population dynamics of this species at small spatial scales $\left(<2 \mathrm{~km}^{2}\right)$. We found considerable site-specific differences in the age structure of $L$. harak, with protected sites having greater mean ages and lower total mortality. There was indication of density-dependent growth as greater size-atage occurred in fished sites where biomass had been depleted. Although female L. harak reach $50 \%$ maturity at $208 \mathrm{~mm}$ fork length (FL) or age $3.8 \mathrm{yr}$, it is the largest and oldest females (>260 mm FL and $>9 \mathrm{yr}$ ) who make a disproportionate contribution to overall reproductive output, as ovary weight increases exponentially with both length and age. Currently size $\left(L_{c}\right)$ and age $\left(t_{c}\right)$ at first capture is $\sim 100 \mathrm{~mm}$ and $2 \mathrm{yr}$ below the size $\left(L_{50}\right)$ and age $\left(t_{50}\right)$ at first maturity. Numerous management scenarios based on minimum size limits were evaluated to determine which scenario would increase spawning biomass without compromising yield estimates. Our results demonstrate that effective implementation of MPAs allows a larger and older population to accrue, thus yielding considerable reproductive benefits.
\end{abstract}

KEY WORDS: MPA · Fishing effects · Demography - Lethrinus harak · Guam · Otoliths · Density-dependent growth

\section{INTRODUCTION}

Effective management of coral reef fisheries is inherently difficult for many reasons. On a typical IndoPacific coral reef, up to 300 species of fish are harvested for food. Numerous fishing methods are utilized, which can be selective and unselective, targeting multiple species at varying rates (Munro 1980). Coral reef fish are also more susceptible to overfishing compared with pelagic or temperate fishes because of their life-history characteristics (Russ 1991). They have small home ranges (Sale 1978), a high degree of habi- tat selectivity (Sluka \& Sullivan 1996), and complex sexual patterns and reproductive behaviors (Shapiro 1987). Additionally, some species have long life-spans (Choat \& Axe 1996) and corresponding low rates of natural mortality and late-onset maturity (Manooch 1987, Pears et al. 2006), all factors which predispose species to overfishing. Furthermore, the assessment of many tropical fish stocks is hampered by the lack of data on historical catch and effort and species-specific biological parameters (Russ 1991).

Marine protected areas (MPAs) are considered a highly effective and practical conservation and fish- 
eries management tool for tropical coral reef fisheries (Polunin 1990, Roberts et al. 2001). If adequately enforced, fish populations within MPAs usually increase in abundance, biomass, mean size, and reproductive potential of target species (Bohnsack 1990). However, monitoring fish size alone may fail to detect differences in the demographic profile of a species and does not provide a complete picture of population recovery in the absence of fishing. For example, differences in the age structure of Plectropomus leopardus between open and closed reefs were more obvious than differences in the size structure which were undetectable (Ferreira \& Russ 1995). Similar studies that have investigated the effects of MPAs on the demography of coral reef fish populations are rare (but see Buxton 1993, Russ et al. 1998, Adams et al. 2000, Begg et al. 2005). Such investigations are enhanced by coupling age data with detailed reproductive analyses, an approach which is imperative for protogynous hermaphrodites. Pears et al. (2006) showed female Epinephelus fuscoguttatus make little or no reproductive contribution until $9 \mathrm{yr}$ of age. Similarly, a response to fishing pressure was sex-specific for $P$. leopardus, which was further complicated by regional plasticity in male sexual strategy (Adams et al. 2000). The accumulation of older age classes in reef fish populations is perhaps the underlying process (by hedging against recruitment failure) which drives the effectiveness of MPAs (Buxton 1993). This is pertinent to many coral reef fish species that have considerable longevity, some spanning many decades (Manooch 1987, Choat \& Axe 1996, Choat et al. 1996). Hence, permanent closure to fishing results in an 'intact' age structure that is close to an unexploited state (Roberts et al. 2005). Moreover, by retaining older females, the chance of fecundity limitation may be reduced, as studies on a limited number of species have indicated that older individuals produce greater numbers of eggs (Bobko \& Berkeley 2004) and their hatched larvae have greater growth and survival rates (Berkeley et al. 2004).

While plasticity in growth is a direct result of the dynamic environment in which coral reef fish live, it is further complicated by the effects of fishing (Rijnsdorp \& van Leeuwen 1992). For example, as the maximum size of the Caribbean scarid Sparisoma viride increased with latitude, growth was also influenced by variable fishing intensity over the same spatial scale (Choat et al. 2003). Similar demographic plasticity has also been demonstrated for non-herbivorous reef fish, with considerable differences in Lethrinus miniatus growth over distances ranging from 20 to $600 \mathrm{~km}$ (Williams et al. 2003). These were attributed to historic differences in fishing pressure and regional differences in population productivity. Growth trajectories and maximum size of numerous unexploited reef spe- cies differed between mid-shelf and outer-shelf reefs on the Great Barrier Reef (GBR) as a result of densitydependent processes such as differential mortality (Gust et al. 2002). The response of a fish population to fishing pressure is highly dependent on the species' demographic profile, particularly that of growth and mortality. It follows that considerable spatial variability in either of these parameters would produce equally variable fisheries yields (Beverton \& Holt 1957). For managers of reef fish stocks it is therefore critical to identify and measure this variability to determine which spatial scale is of greatest importance (Sale 1998).

The thumbprint or blackspot emperor Lethrinus harak is a small- to medium-bodied emperor found in a variety of habitats throughout Indo-Pacific reefs from the Red Sea to Japan and Fiji in the West Pacific (Carpenter \& Allen 1989). The species constitutes an important part of many inshore artisanal, commercial, and recreational fisheries (Carpenter \& Allen 1989). On Guam, L. harak is heavily targeted by hook-and-line, spear, and net fisherman and has historically been among the most important species in the inshore fishery. Presently there is no legislation regulating Guam's L. harak fishery, including no restrictions on the size or number of fish landed. It was recently listed as a 'species of greatest conservation need' by the local fisheries agency as harvest levels have declined considerably since the early 1980s, when detailed fishery data was first collected on Guam. Despite its wide geographic distribution and commercial and recreational importance, life-history data for L. harak is scarce. Available data suggests a protogynous sexual pattern (Ebisawa 2006) and moderate longevity (Hilomen 1997). The only reports of spawning behavior are anecdotal and include brief observations of large aggregations within the lagoons of Palau (Johannes 1981). Previous otolith-based studies found the longevity of $L$. harak to be 12 and $15 \mathrm{yr}$ for populations from Fiji and the GBR, respectively (Hilomen 1997 , Lasi 2003).

While most MPA studies focus on quantifying abundance, biomass, and mean size, assimilating life-history data of a species provides a more holistic view of the differences between areas open and closed to fishing (Begg et al. 2005). The presence of well-enforced MPAs on Guam enabled us to take such an approach for Lethrinus harak (local name Mafuté). The present study was also prompted by the lack of basic biological data and recent evidence of dramatic fishery declines. We set out to document site-specific variability in both age structure and growth parameters from numerous sites around the island using fishery-independent sampling. This demographic data was combined with visual survey data to estimate age structures and mor- 
tality schedules. Finally, yield per recruit and spawning biomass per recruit analyses were conducted, providing relevant biological reference points to evaluate the current fishery status of this species.

\section{MATERIALS AND METHODS}

Study sites. To make a valid comparison of the demography of Lethrinus harak between areas open and closed to fishing, focused sampling occurred on the reef flats at 4 principal sites located on the west and south coasts of Guam: Piti Marine Preserve and East Agaña Bay represented protected and fished sites to the west, and Achang Marine Preserve and Rios Bay represented protected and fished sites to the south (hereinafter referred to as Piti, East Agaña, Achang, and Rios, respectively) (Fig. 1). Piti and Achang MPAs, established in May 1997, were fully enforced in January 2001. At certain times of the year, limited shorebased fishing for culturally important reef fish species (juvenile Siganus spp. and Mulloidichthys flavolineatus) is allowed for permit holders using cast nets and hook and line. All sites represent enclosed reef flats ranging from 0.9 to $1.7 \mathrm{~km}^{2}$.

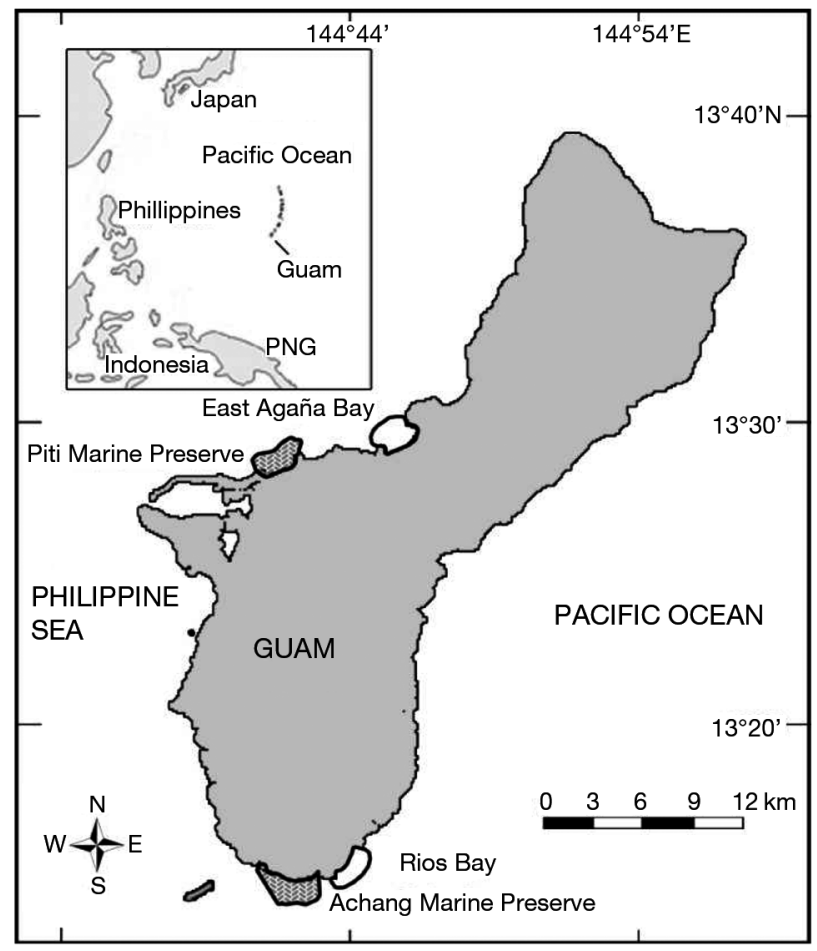

Fig. 1. Map of Guam indicating the 4 study sites. Closed sites (filled): Piti Marine Preserve to the north and Achang Marine Preserve to the south. Fished sites (no fill): East Agaña Bay to the north and Rios Bay to the south
Sampling. Fishery-independent sampling of individual Lethrinus harak occurred on the reef flat between June 2007 and June 2008 using spearfishing or hook and line. A total of 238 fish were caught from the 4 sites: Piti $(n=68)$, East Agaña $(n=76)$, Achang $(n=63)$, and Rios $(\mathrm{n}=31)$. East Agaña and Achang samples were collected exclusively using hook and line, Rios samples using spear, and Piti samples using both methods (71\% hook and line, $29 \%$ spear). Additional samples $(n=178)$ were obtained from the reef flats of 8 additional unprotected sites around Guam using only spearfishing. These samples were included in agebased analyses to estimate overall growth parameters and age structures that were not site-specific. After collection, all samples were placed on ice and immediately returned to the lab for processing. Measurements were taken of fork (FL) and total length (TL) to the nearest millimeter and total (TW) and gutted weight (GW) to the nearest gram. Sagittal otoliths were removed, cleaned in ethanol, weighed to the nearest $0.001 \mathrm{~g}$, and stored dry until sectioning. The relationship between FL and GW was estimated for all sites and sexes using regression analysis. These variables were transformed using $\log _{\mathrm{e}} x$ to linearize the power curve describing the relationship, and analysis of covariance (ANCOVA) was used to compare the relationship between transformed FL and GW between sexes with weight as the dependent variable, length as the covariate, and sex as the categorical variable.

Probability of capture across the size and age range of Lethrinus harak for each gear type was estimated using backwards extrapolation of catch curves. Selectivity curves were produced by fitting a logistic function to the data, which was done separately for samples from spear and hook and line. Probability of capture was also estimated for the entire fishery using backwards extrapolation of length-converted catch curves for historical creel survey data provided by the Guam Division of Aquatic and Wildlife Resources to be used in per-recruit analyses.

Reproduction. Gonads of each specimen were blotted dry, weighed to the nearest $0.001 \mathrm{~g}$, and preserved in FAACC (formaldehyde $4 \%$, acetic acid $5 \%$, calcium chloride $1.3 \%$ ). Sex and maturity stages were determined macroscopically and later confirmed using microscopic (histology) techniques. Classification of female maturity stages followed criteria outlined in West (1990) and was based on the presence or absence of the following oocyte stages: chromatin nucleolar, perinucleolar oocytes, cortical alveoli, vitellogenic, and ripe. Size and age at $50 \%$ maturity were estimated by plotting the proportion of mature individuals against length and age classes and fitting a logistic equation to the data. To explore the relationship between female body size, age, and reproductive capacity, the ovary 
weights of mature, active females were plotted against size and age class. Sex ratios were compared among age classes using a $\chi^{2}$ test.

Otolith processing and age determination. Sagittal otoliths were mounted in thermoplastic (Crystalbond 509) adhesive on the edge of a microscope slide and ground to the nucleus using 600 grit wet/dry paper fitted to a GEMMASTA GFL8 lapping wheel. The ground face of the otolith was fixed on the slide and the opposite side ground to produce a thin transverse section $~ 300 \mu \mathrm{m}$ thick. Each section was covered in adhesive and placed on a hotplate $\left(230^{\circ} \mathrm{C}\right)$ for $\sim 30$ min to improve the readability of the opaque bands. These were examined under transmitted light with a low power microscope (20 to $40 \times$ ). Annuli (represented by alternating translucent and opaque bands) were counted along a consistent axis on the ventral face of the section. Blind readings were made on 3 separate occasions 1 to $2 \mathrm{wk}$ apart. The final age (in years) of an individual was determined when 2 or more counts agreed (Choat \& Axe 1996). The relationship between age and otolith weight was assessed using regression analysis. ANCOVA was used to compare this relationship between sexes with age as the dependent variable, otolith weight as the covariate, and sex as the categorical variable.

The assumption that otolith increments were annual was tested using oxytetracycline (OTC) marking. Five wild-caught Lethrinus harak were tagged with individually coded T-bar anchor tags, injected with $50 \mathrm{mg}$ $\mathrm{kg}^{-1}$ total weight OTC solution (Liquamycin LA-200 as oxytetracycline dehydrate at $200 \mathrm{mg} \mathrm{ml}^{-1}$ ), and kept in an outdoor aquarium for a period of $>1 \mathrm{yr}$. These fish were fed every morning with a mix of squid and clam until satiated. After $\sim 15$ mo in captivity, the otoliths were removed and a thin transverse section was produced as described above (see 'Otolith processing and age determination'). The presence of an OTC mark on individual otoliths was identified using ultravioletilluminated microscopy. Digital images of the otoliths were obtained and Image J software used to measure increment widths outside the OTC mark along the proximal edge parallel to the sulcus groove. To determine the periodicity the following formula from Pears et al. (2006) was applied:

$$
P=\frac{x}{y \times G}
$$

where $P$ is the periodicity of increment formation $\left(\mathrm{yr}^{-1}\right)$, $x$ is the distance $(\mathrm{mm})$ from the OTC mark to the otolith edge, $y$ is the distance $(\mathrm{mm})$ between the last 2 increments, and $G$ is the growth period (yr) after injection.

Age and growth. The von Bertalanffy growth function (VBGF) was fitted to length-at-age estimates using non-linear least-squares estimation. The VBGF is represented by

$$
L_{t}=L_{\infty}\left\{1-\exp \left[-K\left(t-t_{0}\right)\right]\right\}
$$

where $L_{t}$ is the FL of a fish at age $t, L_{\infty}$ is the mean asymptotic FL, $K$ is the growth coefficient that describes the rate at which fish grow towards $L_{\infty} t$ is the age of the fish, and $t_{0}$ is the theoretical age at which $\mathrm{FL}=0$, as described by the growth rate. To promote a better fit to the size-at-age data, no constraint for size at settlement was placed upon the $y$-intercept. Individuals $<1$ yr old $(0+$ individuals $)$ were excluded from the growth estimations because accurate ages (e.g. months old) for these individuals were not possible. Growth parameters were compared between sexes and among sites using bivariate $95 \%$ confidence ellipses surrounding the $K$ and $L_{\infty}$ estimates (Kimura 1980) and the analysis of residual sums of squares (ARSS) method (Chen et al. 1992). Mean size-at-age was compared among sites and protection statuses for ages 1 through 4 yr using ANOVA.

Demography. Length-at-age data from the otolith analysis were used to construct protection-specific age-length keys, which in turn were used to convert length-frequency distribution data collected during underwater visual census (UVC) into age frequencies (Ricker 1975). Two age-length keys were created because of differences in size-at-age between protected and unprotected sites. While not commonly used by coral reef ecologists, this technique has been applied to fisheries data from commercial landings whereby annual age-length keys and lengthfrequency distributions are combined to produce estimates of annual landings in numbers at age (e.g. Vaughan et al. 1992, Grandcourt et al. 2006). The UVC were conducted by snorkeling on the reef flats among all representative habitat types (e.g. seagrass, coral reef, sand, coral rubble). Samples of Lethrinus harak were taken from these same areas, but only on completion of the UVC. Individual L. harak encountered along each transect $(50 \times 5 \mathrm{~m})$ were counted and allocated to a $3 \mathrm{~cm}$ size class. A total of 316 transects were conducted during a 4 mo period (June 2007 to October 2007; East Agana = 90; Piti = 89; Achang = 83; Rios $=$ 54). All counts were done by 1 observer (B. M. Taylor), who was trained in estimating fish size. To minimize the influence of tide and time of day, all surveys were conducted during morning hours ( 08:00 to $\sim 11: 00 \mathrm{~h})$ and within $\pm 2 \mathrm{~h}$ of the high tide. The start of each transect was chosen haphazardly and marked with a handheld GPS unit (Garmin eTrex ${ }^{\circledR}$ ). These GPS coordinates were entered onto a digital habitat map of each site to ensure no transects overlapped.

Estimates of demographic parameters were obtained from both the fishery-independent raw catch data (RC) 
and the length-converted data (LC). Using the agelength keys, age frequencies were calculated for each of the 4 surveyed sites from the size frequency distributions compiled during the UVCs. This was done by grouping fish of a known age into $30 \mathrm{~mm}$ length intervals. The proportion of fish of each observed age was computed for each length class and this was summed across length classes to produce site-specific age frequency distributions (Ricker 1975). Unlike fisherydependent data, which is often biased by gear selectivity, this method produces distributions that are a more robust estimate of the population, particularly as all life stages of Lethrinus harak were present and quantifiable in the reef flat where the UVC took place. For RC data, age frequency distributions were estimated by plotting the frequency of individuals per age class. Mean age was compared between sexes for RC data, and among sites for both LC and RC data using ANOVA.

Site-specific estimates of total mortality were obtained using age-based catch curves from both the $\mathrm{LC}$ and RC data. The natural logarithm of the number of fish in each age class was plotted against its corresponding age, and total mortality (Z) was estimated as the absolute value of the slope from a fitted line (Ricker 1975). Age classes that had not fully recruited to the fishery (based on selectivity curves) were excluded from this. A modified $t$-test was used to compare estimates of $\mathrm{Z}$ from age-based catch curves among sites and between data sets (LC vs. RC). For Piti and Achang MPAs, where Lethrinus harak populations are not exploited, estimates of $\mathrm{Z}$ were considered equal to natural mortality (M) (Bohnsack 1990, Russ et al. 1998). Estimates of $M$ were also calculated for each site using the general equations of Pauly (1980):

$\log _{10} \mathrm{M}=-0.0066-0.279 \times \log _{10} L_{\infty}+0.6543 \times \log _{10} K+$ $0.4634 \times \log _{10} T$

which is based on VBGF parameters ( $L_{\infty}$ and $K$ ) and mean seawater temperature $(T)$; and Hoenig (1983):

$$
\log _{\mathrm{e}} \mathrm{Z}=1.46-1.01 \times \log _{\mathrm{e}} t_{\max }
$$

The equation of Hoenig (1983) was used to estimate $\mathrm{M}$ where $\mathrm{M}=\mathrm{Z}$ in an unexploited population, so the maximum age estimate $\left(t_{\mathrm{max}}\right)$ was set at $15 \mathrm{yr}$ following Hilomen (1997) assuming this is the maximum age for the species in Guam. The mean annual seawater temperature around Guam is $29^{\circ} \mathrm{C}$ (Coral Reef Watch, NOAA Satellite and Information Service, NESDIS). Fishing mortality $(\mathrm{F})$ for the non-protected sites was estimated by subtracting M (calculated using Hoenig's (1983) equation) from $\mathrm{Z}$.

Fishery assessment. The status of Guam's Lethrinus harak stock was assessed using a per-recruit analysis
(Beverton \& Holt 1957). Spawner biomass per recruit (SBR) and yield per recruit (YPR) were calculated for fishing mortalities ranging from 0 to 1 to evaluate the effects of modifying the instantaneous fishing mortality and the size or age at first capture. The SBR was calculated as follows:

$$
\mathrm{SBR}=\mathrm{SB} / \mathrm{R}=\sum_{t=0}^{t_{\max }} \exp \left\{-\left[\left(\mathrm{F} \times S_{t}\right)-\mathrm{M}\right] t\right\} W_{t} \mathrm{G}_{t}
$$

where SB is the total spawner biomass (in $\mathrm{g}$ ), $\mathrm{R}$ is the number of recruits (set to 1 ), $F$ and $M$ are the fishing and natural mortality rates, respectively, $W_{t}$ is the weight at age $t, t_{\max }$ is the maximum observed age in the fishery (calculated in months), and $\mathrm{G}_{\mathrm{t}}$ and $S_{\mathrm{t}}$ are the fraction of mature fish and the gear selectivity at age $t$, respectively. Maturity and selectivity were logistic equations calculated as the proportion of mature individuals and the probability of capture by age.

Growth parameters from the unconstrained VBGF fitted to weight-at-age data and $M$ (calculated using Hoenig's [1983] equation) were used to construct the YPR stock assessment model as follows:

$$
\mathrm{YPR}=\mathrm{Y} / \mathrm{R}=\sum_{t_{c}}^{t_{\max }} \mathrm{F} N_{t} W_{t}
$$

where $\mathrm{Y}$ is yield, $t_{c}$ is the age at first capture, $t_{\max }$ is the maximum age in the fishery, $N_{t}$ is the number of individuals alive at age $t$. We employed a modified version of the classic Beverton \& Holt (1957) YPR model (taken from Sparre et al. 1989) to estimate yield for various sizes or ages at first capture across a range of fishing mortalities.

\section{RESULTS}

Between 5 June 2007 and 20 June 2008, a total of 416 Lethrinus harak, ranging in size from 83 to 327 mm FL, were collected from sites on Guam (Table 1, Fig. 2A). These individuals ranged in age from $<1$ to $13 \mathrm{yr}$. Of these, 328 were identified as females (age $<1$ to $11 \mathrm{yr}$ ), while 85 were males (age 3 to 13 yr). Both sexes had a strong length-weight relationship, the slopes of which did not differ significantly (ANCOVA: $F_{1,405}=0.267$, $\mathrm{p}=0.61$ ) (Table 1). Although females on average (185 mm FL) were much smaller than males (240 mm FL), they reached a larger maximum size (Table 1, Fig. 2A). There was considerable variability between size at $50 \%$ probability of capture $\left(L_{50}\right)$ between collection methods (spear: $L_{50}=189 \mathrm{~mm} \mathrm{FL}, \mathrm{r}^{2}=0.99$; hook and line: $\left.L_{50}=159 \mathrm{~mm} \mathrm{FL}, \mathrm{r}^{2}=0.99\right)$. The overall selectivity curve derived from length-converted historical catch data ranged from 105 to $205 \mathrm{~mm} \mathrm{FL}$, with $L_{50}$ at $160 \mathrm{~mm}$ FL $\left(\mathrm{r}^{2}=0.99\right)$. 
Table 1. Lethrinus harak. Results of the regression analyses describing the length-weight relationships for all sites and both sexes. FL = fork length, GW = gutted weight, Min-max = range of minimum and maximum values

\begin{tabular}{|c|c|c|c|c|c|c|c|c|}
\hline & $\mathrm{n}$ & $a$ & $b$ & $\mathrm{r}^{2}$ & $\begin{array}{l}\text { Min-max FL } \\
(\mathrm{mm})\end{array}$ & $\underset{(g)}{\operatorname{Min}-\max _{\text {mW }} \text { GW }}$ & $\begin{array}{c}\text { Mean FL } \pm \text { SE } \\
(\mathrm{mm})\end{array}$ & $\begin{array}{c}\text { Mean } \mathrm{GW}_{(\mathrm{g})} \pm \mathrm{SE} \\
\end{array}$ \\
\hline \multicolumn{9}{|l|}{ Site } \\
\hline Piti MPA & 68 & $2 \times 10^{-5}$ & 2.982 & 0.992 & $110-327$ & $24-700$ & $211.1 \pm 5.7$ & $193.7 \pm 15.4$ \\
\hline East Agaña Bay & 76 & $2 \times 10^{-6}$ & 3.396 & 0.995 & $85-254$ & 8-292 & $171.5 \pm 4.7$ & $105.7 \pm 7.6$ \\
\hline Achang MPA & 63 & $2 \times 10^{-5}$ & 2.993 & 0.995 & $108-251$ & $22-298$ & $180.5 \pm 5.0$ & $125.1 \pm 9.1$ \\
\hline Rios Bay & 31 & $2 \times 10^{-5}$ & 2.981 & 0.983 & $151-251$ & $61-296$ & $205.9 \pm 4.6$ & $169.0 \pm 10.4$ \\
\hline \multicolumn{9}{|l|}{ Sex } \\
\hline Female & 328 & $8 \times 10^{-6}$ & 3.162 & 0.990 & $83-327$ & 8-700 & $185.4 \pm 2.3$ & $134.2 \pm 4.7$ \\
\hline Male & 85 & $2 \times 10^{-5}$ & 2.959 & 0.950 & $179-293$ & $110-456$ & $239.9 \pm 2.6$ & $257.5 \pm 8.3$ \\
\hline Combined & 413 & $9 \times 10^{-6}$ & 3.123 & 0.991 & $83-327$ & $8-700$ & $196.4 \pm 2.2$ & $158.9 \pm 4.8$ \\
\hline
\end{tabular}

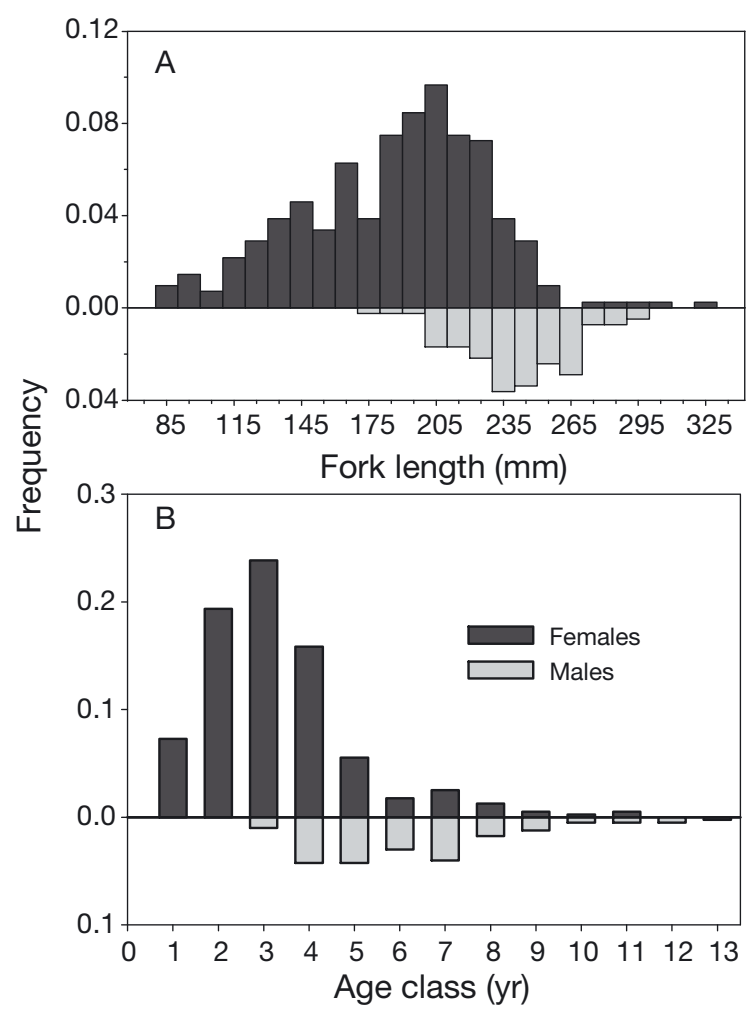

Fig. 2. Lethrinus harak. (A) Size-frequency distributions for females $(n=328)$ and males $(n=85)$ and $(B)$ age-frequency distributions for females $(n=313)$ and males $(n=85)$ collected from various sites around Guam using fishery-independent raw catch data

\section{Aging and validation}

Annuli were identified in 398 of the 415 otoliths examined $(96 \%)$. The increments of older fish (age $>4 \mathrm{yr}$ ) were easier to interpret compared with younger fish (age $<1$ to $4 \mathrm{yr}$ ). Otolith weight was a good predictor of age for both males $\left(\mathrm{r}^{2}=0.79, F_{1,83}=306, \mathrm{p}<\right.$
Table 2. Lethrinus harak. Relationship between age (yr) and otolith weight (OtoWt, g) at all sites and between sexes using regression analysis

\begin{tabular}{|lrcccc|}
\hline & $\mathrm{n}$ & Equation & $\mathrm{r}^{2}$ & $\mathrm{p}$ \\
\hline Site & & & & \\
Piti MPA & 68 & Age $=85.9($ OtoWt $)-0.66$ & $0.91<0.001$ \\
East Agaña & 67 & Age $=80.2($ OtoWt $)-0.21$ & $0.85<0.001$ \\
Bay & & & & \\
Achang MPA & 63 & Age $=74.0($ OtoWt $)-0.16$ & $0.88<0.001$ \\
Rios Bay & 31 & Age $=84.7($ OtoWt $)-0.97$ & $0.83<0.001$ \\
Sex & & & & \\
Female & 308 & Age $=69.4($ OtoWt $)+0.08$ & $0.86<0.001$ \\
Male & 85 & Age $=81.3($ OtoWt $)-0.69$ & $0.79<0.001$ \\
Combined & 393 & Age $=73.3($ OtoWt $)-0.08$ & $0.88<0.001$ \\
\end{tabular}

$0.001)$ and females $\left(\mathrm{r}^{2}=0.87, F_{1,307}=1852, \mathrm{p}<0.001\right)$ (Table 2). Slopes of these relationships differed significantly between the sexes $\left(F_{1,386}=12.3, \mathrm{p}<0.001\right)$.

The OTC-marking experiment confirmed increment formation is annual. At the end of the experiment, fish ranged in age from 3 to $5 \mathrm{yr}$. The calculated periodicity ranged from $1.04 \mathrm{yr}^{-1}$ to $1.14 \mathrm{yr}^{-1}$. The higher estimates occurred in younger fish (age $3 \mathrm{yr}$ ), which is expected given that differences in individual growth rates during the experiment would be greater for younger (age 3 yr) compared with older fish (age 5 yr).

\section{Age structure and mortality}

Fishery-independent RC data were used to compare male and female age distributions. While there was considerable overlap between male and female age distributions, the males had a significantly greater mean age (6.1 vs. 3.3 yr; $F_{1,392}=157.7, \mathrm{p}<0.001$; Fig. 2B). The sex ratios among age classes were very 


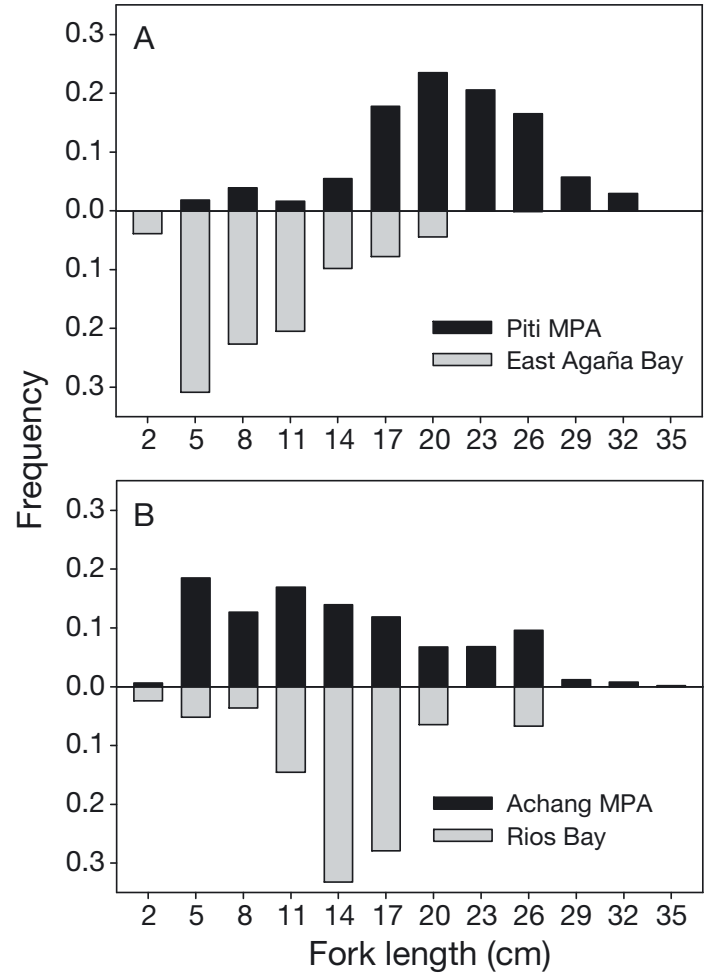

Fig. 3. Lethrinus harak. Length-frequency distributions for (A) Piti Marine Preserve and East Agaña Bay and (B) Achang Marine Preserve and Rios Bay derived from underwater visual census different, with individuals beyond 6 yr predominantly male $\left(\chi^{2}=235, \mathrm{df}=13, \mathrm{p}<0.001\right)$.

Site-specific age structures from RC data indicate that individuals $>8 \mathrm{yr}$ old were found only at 1 study site (Piti). However, length frequencies from UVC data indicate that $12 \%$ of Achang's Lethrinus harak population is between 25 and $36 \mathrm{~cm}$ FL (Fig. 3), but the largest individual collected from Achang was only $25.1 \mathrm{~cm}$ FL (Table 1), indicating that larger (and presumably older) individuals from Achang were undersampled. Hence, age-length keys (Table 3) were combined with length-frequency distributions from UVC (Fig. 3) to correct for sampling error and provide better estimates of age structure. Comparison of these LC estimates revealed that the protected sites Piti and Achang had a greater proportion of fish in older age classes while East Agaña and Rios were heavily truncated (Fig. 4). Using LC data, fish aged $>5 \mathrm{yr}$ comprise $40 \%$ of Piti's and $16 \%$ of Achang's $L$. harak population. By comparison, these individuals make up $<1 \%$ and $7 \%$ of that within East Agaña and Rios. Such differences translated into significantly greater mean ages in Piti (LC: Piti $=5.4$ yr vs. East Agaña $=0.72$ yr; $F_{1,909}=1035, \mathrm{p}<0.001 ;$ RC: Piti $=$ $5.1 \mathrm{yr}$ vs. East Agaña $=2.4 \mathrm{yr} ; F_{1,142}=46, \mathrm{p}<0.001$ ) but not in Achang (LC: Achang $=2.6$ yr vs. Rios $=2.0$ $\mathrm{yr}_{i} F_{1,871}=3.3, \mathrm{p}=0.07 ; \mathrm{RC}$ : Achang $=3.7 \mathrm{yr}$ vs. Rios $=4.2 \mathrm{yr}_{;} F_{1,93}=1.9, \mathrm{p}=0.17$ ).
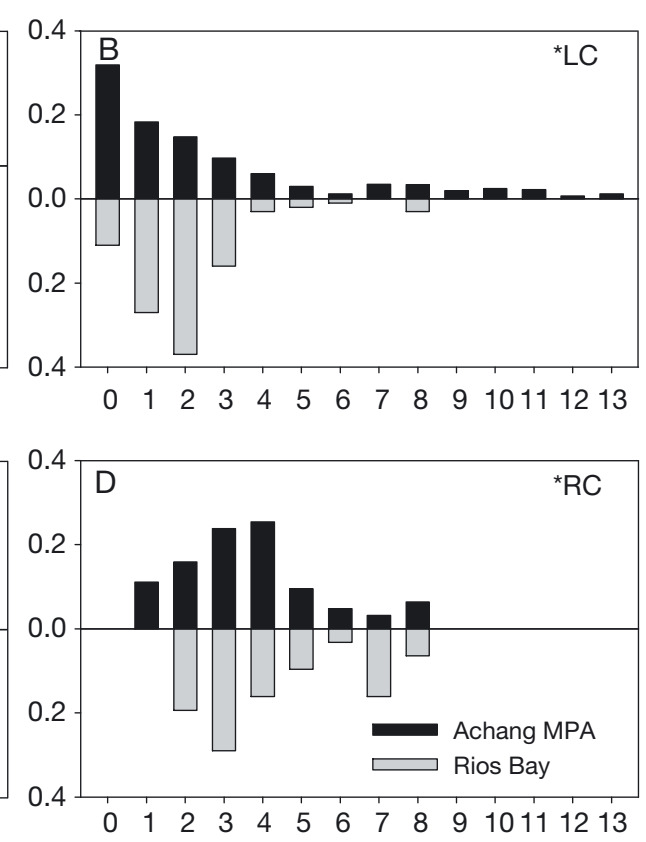

Age class (yr)

Fig. 4. Lethrinus harak. Age-frequency distributions from the 4 study sites. (A,B) Data derived by extrapolating length-frequency data from visual surveys using an age-length key. (C,D) Data derived from fishery-independent catch-at-age data. Black or grey bars: sites closed or open to fishing, respectively. Sample size: (A) Piti, $\mathrm{n}=243$; East Agaña, $\mathrm{n}=667$; (B) Achang, $\mathrm{n}=772$; Rios, $\mathrm{n}=100 ;(\mathrm{C})$ Piti, $\mathrm{n}=68$; East Agaña, $\mathrm{n}=76$; (D) Achang, $\mathrm{n}=63$; Rios, $\mathrm{n}=31$. LC = length-converted data, RC = raw catch data 
Table 3. Lethrinus harak. The observed age-length key for (A) protected sites and (B) unprotected sites. Size classes are midpoints of $30 \mathrm{~mm}$ size classes (fork length)

\begin{tabular}{|c|c|c|c|c|c|c|c|c|c|c|c|c|c|c|c|}
\hline \multirow{2}{*}{ Size class $(\mathrm{mm})$} & \multicolumn{14}{|c|}{ Age (yr) } & \multirow[t]{2}{*}{ Total } \\
\hline & 0 & 1 & 2 & 3 & 4 & 5 & 6 & 7 & 8 & 9 & 10 & 11 & 12 & 13 & \\
\hline \multicolumn{16}{|c|}{ (A) Protected sites } \\
\hline 25 & & & & & & & & & & & & & & & 0 \\
\hline 55 & & & & & & & & & & & & & & & 0 \\
\hline 85 & & & & & & & & & & & & & & & 0 \\
\hline 115 & & 8 & & & & & & & & & & & & & 8 \\
\hline 145 & & 2 & 17 & 3 & & & & & & & & & & & 22 \\
\hline 175 & & & 7 & 10 & 4 & & & & & & & & & & 21 \\
\hline 205 & & & & 12 & 18 & 7 & 1 & & & & & & & & 38 \\
\hline 235 & & & & & 2 & 7 & 4 & 9 & 3 & 2 & & & & & 27 \\
\hline 265 & & & & & & & & 1 & 2 & 1 & 2 & 1 & & 1 & 8 \\
\hline 295 & & & & & & & & & 1 & 1 & & 1 & 2 & & 5 \\
\hline 325 & & & & & & & & & & & & 1 & & & 1 \\
\hline Total & & 10 & 24 & 25 & 24 & 14 & 5 & 10 & 6 & 4 & 2 & 3 & 2 & 1 & 130 \\
\hline \multicolumn{16}{|c|}{ (B) Unprotected sites } \\
\hline 25 & & & & & & & & & & & & & & & 0 \\
\hline 55 & & & & & & & & & & & & & & & 0 \\
\hline 85 & 9 & & & & & & & & & & & & & & 9 \\
\hline 115 & & 3 & & & & & & & & & & & & & 3 \\
\hline 145 & & 4 & 7 & & & & & & & & & & & & 11 \\
\hline 175 & & & 17 & 16 & 1 & & & & & & & & & & 34 \\
\hline 205 & & & 7 & 15 & 7 & 1 & & 1 & & & & & & & 31 \\
\hline 235 & & & & 1 & 3 & 6 & 2 & 4 & 1 & & & & & & 17 \\
\hline 265 & & & & & & & 1 & & 1 & & & & & & 2 \\
\hline 295 & & & & & & & & & & & & & & & 0 \\
\hline 325 & & & & & & & & & & & & & & & 0 \\
\hline Total & 9 & 7 & 31 & 32 & 11 & 7 & 3 & 5 & 2 & 0 & 0 & 0 & 0 & 0 & 107 \\
\hline
\end{tabular}

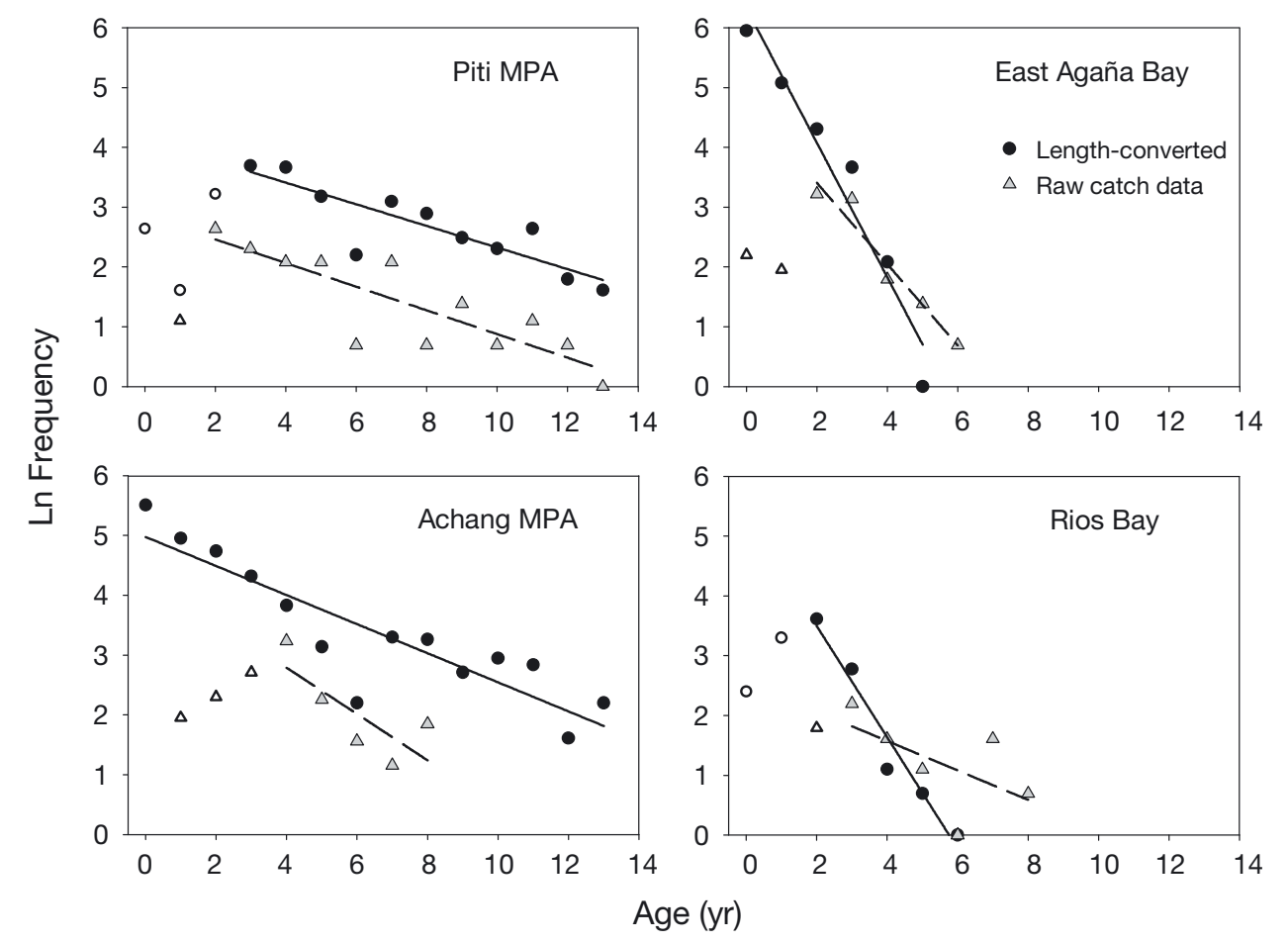

Fig. 5. Lethrinus harak. Age-based catch curves for length-converted and raw catch data from (A) Piti Marine Preserve, (B) East Agaña Bay, (C) Achang Marine Preserve, and (D) Rios Bay. Solid or dashed lines show the linear regression equation for lengthconverted or raw catch data catch curves, respectively. Only filled points are included in regressions 
Table 4. Lethrinus harak. Estimates of instantaneous rates of total mortality (Z) derived from age-based catch curves, Pauly's natural mortality (M), fishing mortality $(\mathrm{F})$, and exploitation ratio (E) for all sites. $\mathrm{F}=\mathrm{Z}-\mathrm{M}$, where $\mathrm{M}=0.294 \mathrm{yr}^{-1}$ from Hoenig's (1983) equation. LC = length-converted data, $\mathrm{RC}=$ raw catch data. na $=$ not applicable

\begin{tabular}{|lcccc|}
\hline $\begin{array}{l}\text { Site } \\
\mathrm{r}^{2}\end{array}$ & $\begin{array}{c}\mathrm{Z} \\
\left(\mathrm{yr}^{-1}\right)\end{array}$ & $\begin{array}{c}\text { Pauly's M } \\
\left(\mathrm{yr}^{-1}\right)\end{array}$ & $\begin{array}{c}\mathrm{F} \\
\left(\mathrm{yr}^{-1}\right)\end{array}$ & $\begin{array}{c}\mathrm{E} \\
(\mathrm{F} / \mathrm{Z})\end{array}$ \\
\hline $\begin{array}{l}\text { Piti MPA } \\
\text { LC: 0.75 }\end{array}$ & 0.181 & 0.717 & na & na \\
$\quad$ RC: 0.72 & 0.198 & & & \\
$\begin{array}{l}\text { East Agaña Bay } \\
\text { LC: 0.95 }\end{array}$ & 1.125 & 0.723 & 0.831 & 0.739 \\
$\quad$ RC: 0.95 & 0.680 & & & \\
Achang & & & & \\
$\quad$ MPALC: 0.80 & 0.243 & 0.632 & na & na \\
$\quad$ RC: 0.60 & 0.387 & & & \\
Rios Bay & & & & \\
LC: 0.96 & 0.930 & 1.107 & 0.636 & 0.684 \\
RC: 0.35 & 0.246 & & & \\
\hline
\end{tabular}

Age-based, site-specific catch curves (using LC data) indicated that the protected sites Piti and Achang had low total mortality rates compared with the exploited sites East Agaña and Rios (Fig. 5, Table 4). By comparison, catch curves from RC data appeared to overestimate mortality for protected sites and underestimate it for fished sites (Fig. 5, Table 4). In addition, catch curve $\mathrm{r}^{2}$ values were typically higher for LC data (Table 4). For protected sites, estimates of $\mathrm{Z}$ did not differ significantly between LC and RC data. Estimates were much more variable at fished sites, however, likely because of fewer age classes in samples and sampling biases associated with RC data. East Agaña estimates differed significantly between data types $(t=2.59$, p < 0.05 , df $=9$ ) whereas the difference for Rios was not significant because of high variability in the RC estimate $(t=0.702, \mathrm{p}=0.510$, $\mathrm{df}=9$ ). Protected sites consistently had significantly lower $Z$ values than their comparative fished sites for both data types with the exception of Achang $\mathrm{RC}$ versus Rios $\mathrm{RC}$ $(t=0.143, \mathrm{p}=0.892, \mathrm{df}=9)$. Age at full recruitment to the fishery for RC data varied among sites due to differences in sizeat-age profiles and collection method. Estimates of M derived from Pauly's (1980) equation often exceeded estimates of $\mathrm{Z}$ from catch curves (Table 4). Hoenig's (1983) model, however, provided an estimate of $M$ that was much more comparable to catch curve estimates from protected sites $\left(0.294 \mathrm{yr}^{-1}\right)$. Hence, Hoenig's estimate was used in per-recruit analyses and to estimate sitespecific F values for unprotected sites.

\section{Growth}

The VBGF revealed that Lethrinus harak has a moderate growth rate, with $\sim 75 \%$ of the mean asymptotic length achieved in the first $4 \mathrm{yr}$ (Fig. 6, Table 5). The overall $K$ and $L_{\infty}$ estimates for this species were 0.265 $\mathrm{yr}^{-1}$ and $281.3 \mathrm{~mm} \mathrm{FL}$, respectively (Table 5). Male and female growth parameters did not differ significantly (ARSS; $F_{3,391}=2.1, \mathrm{p}=0.10$ ). This result was supported by non-overlapping bivariate $95 \%$ confidence ellipses surrounding the parameters $K$ and $L_{\infty}$ (Fig. 6). The ARSS results for growth at the site level were congruent with $95 \%$ bivariate confidence ellipses, which showed that growth profiles differed significantly among sites (Fig. 7). However, large and old individuals were only represented at 1 of 4 sites. Hence, to better compare growth of individuals among sites, mean size-at-age was compared across age classes 1 through 4. There was a general trend in which MPA sites had smaller size-at-age in comparison with unprotected sites (Table 6A). Comparison of size-at-age by protection status suggested that these differences were statistically significant for ages 2 and 4 (Table 6B). Plotting the mean size for age class 2 (where differences were most pronounced) alongside mean biomass estimates from UVC data suggests that growth may be density-dependent, as size-at-age is inversely related to patterns of biomass (Fig. 8).

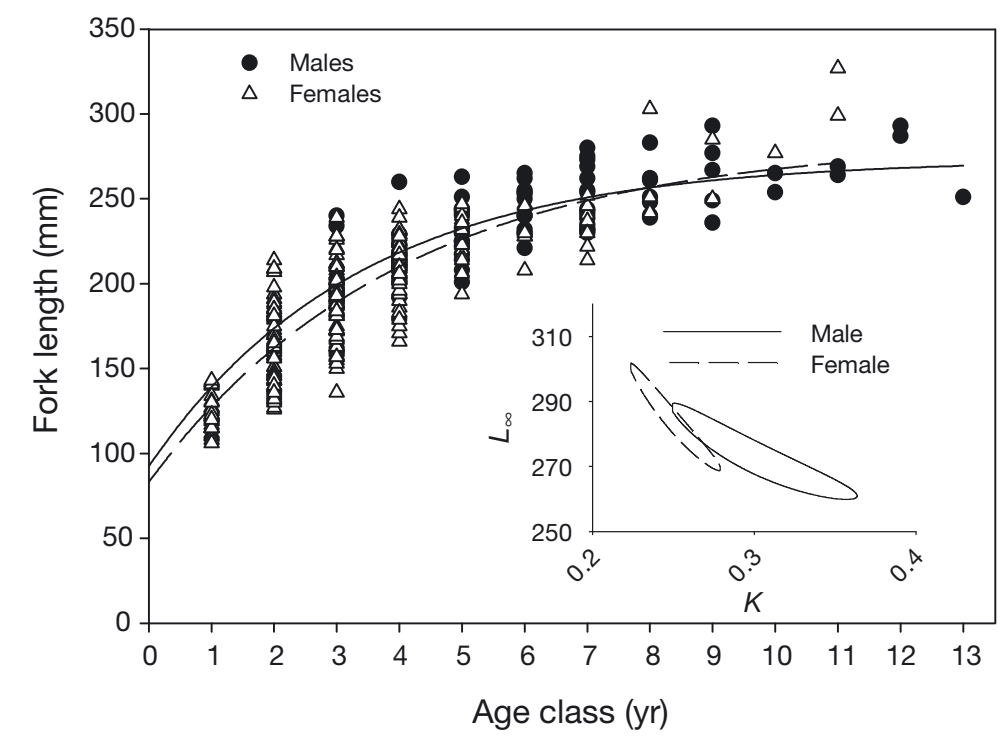

Fig. 6. Lethrinus harak. Von Bertalanffy growth function (VBGF) fitted to size-at-age data for males and females. Inset: $95 \%$ bivariate confidence ellipses surrounding parameters $K$ and $L_{\infty}$ 
Table 5. Lethrinus harak. Von Bertalanffy growth function (VBGF) parameters for all sites and populations examined, using length-at-age data. $\mathrm{CI}=$ confidence interval

\begin{tabular}{|c|c|c|c|c|c|c|c|}
\hline & $\mathrm{n}$ & $L_{\infty}$ & $95 \% \mathrm{CI}$ & $K$ & $95 \% \mathrm{CI}$ & $t_{0}$ & $r^{2}$ \\
\hline \multicolumn{8}{|l|}{ Site } \\
\hline Piti MPA & 68 & 290.0 & $274.8-307.6$ & 0.239 & $0.209-0.272$ & -1.293 & 0.89 \\
\hline East Agaña Bay & 67 & 280.6 & $241.7-344.8$ & 0.239 & $0.170-0.323$ & -1.810 & 0.69 \\
\hline Achang MPA & 63 & 292.8 & $262.8-335.5$ & 0.198 & $0.158-0.243$ & -1.494 & 0.87 \\
\hline Rios Bay & 31 & 240.4 & $226.0-257.9$ & 0.428 & $0.346-0.539$ & -1.072 & 0.72 \\
\hline \multicolumn{8}{|l|}{ Sex } \\
\hline Female & 310 & 284.1 & $268.7-301.8$ & 0.250 & $0.224-0.279$ & -1.386 & 0.74 \\
\hline Male & 83 & 273.2 & 259.9-289.5 & 0.298 & $0.249-0.363$ & -1.385 & 0.51 \\
\hline Combined & 393 & 281.3 & $271.6-292.0$ & 0.265 & $0.246-0.286$ & -1.253 & 0.80 \\
\hline
\end{tabular}

fished sites $\left(\mathrm{F}=0.83\right.$ and $0.64 \mathrm{yr}^{-1}$; Fig. 10). Optimal yield is achieved at higher fishing mortalities ( $\mathrm{F}>0.2 \mathrm{yr}^{-1}$ ) when the size of entry to the fishery is $16 \mathrm{~cm}$ ( 2 yr old). However, this scenario would also result in a corresponding low SBR, similar to that of the current level. In contrast, increasing the size limit to above the size at $50 \%$ maturity ( 23 or $24.5 \mathrm{~cm}$ ) would reduce the YPR at low fishing mortalities compared to the present scenario. But if fishing mortalities at East Agaña and Rios were maintained at current

\section{Reproductive biology}

The gonads of 414 individual Lethrinus harak were examined using both macroscopic and microscopic methods. The overall sex ratio was male: female $=1: 3.8$, though this varied considerably with size and age. Females were the dominant sex in the lower size and age classes whereas the larger and older fish were predominantly males (Figs. $2 \& 3 \mathrm{~A}$ ). When the 2 reproductive staging methods were compared, macroscopic staging was adequate for determining sex (92\% agreement) but inadequate when characterizing maturity status (76\% agreement).

It was found that female Lethrinus harak on Guam reach $50 \%$ maturity at $\sim 208 \mathrm{~mm}$ FL or age $3.8 \mathrm{yr}\left(\mathrm{r}^{2}=0.99\right.$, $\mathrm{p}<0.001$ ). Additionally, there was a strong relationship between female ovary weight and both size and age $\left(\mathrm{r}^{2}=0.71\right.$ and 0.84 , respectively; Fig. 9). Although large and old females were rare in the samples, plots of ovary weight suggest an exponential relationship where females $>260 \mathrm{~mm}$ FL and $>9$ yr are contributing a disproportionately greater amount of eggs.

\section{Fishery assessment}

The per-recruit model (YPR) revealed that the present scenario (no size limit) had among the lowest yield and spawner biomass per recruit (SBR) at current levels of fishing mortality for
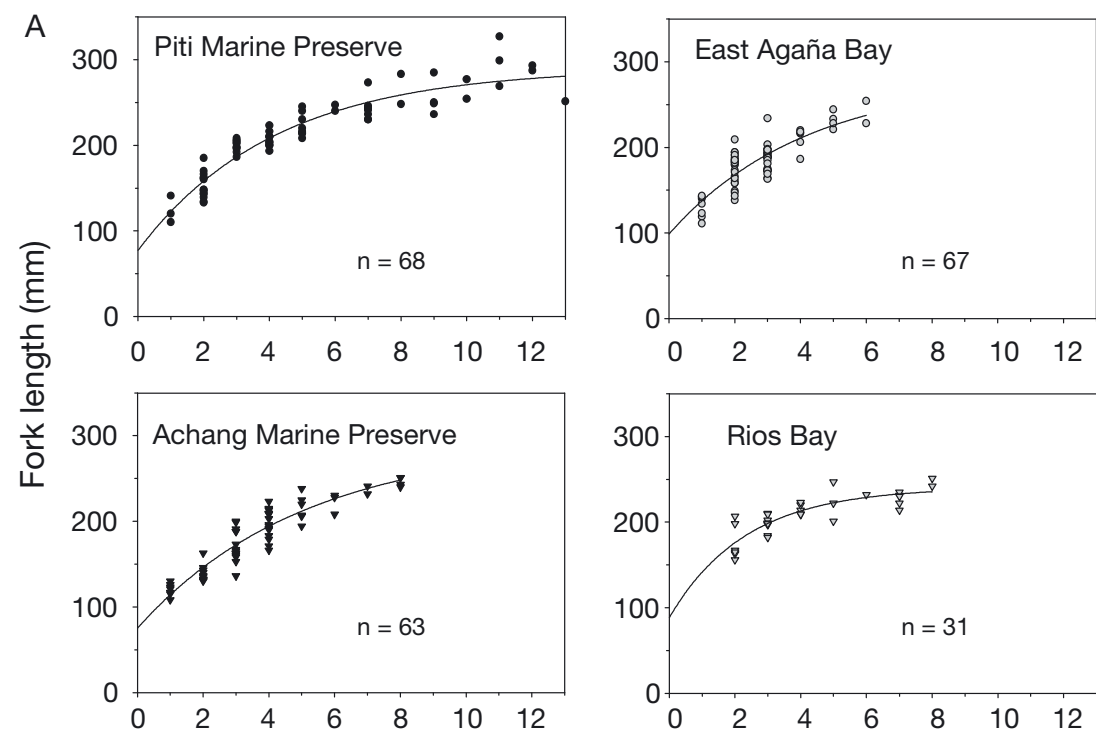

Age class (yr)

B

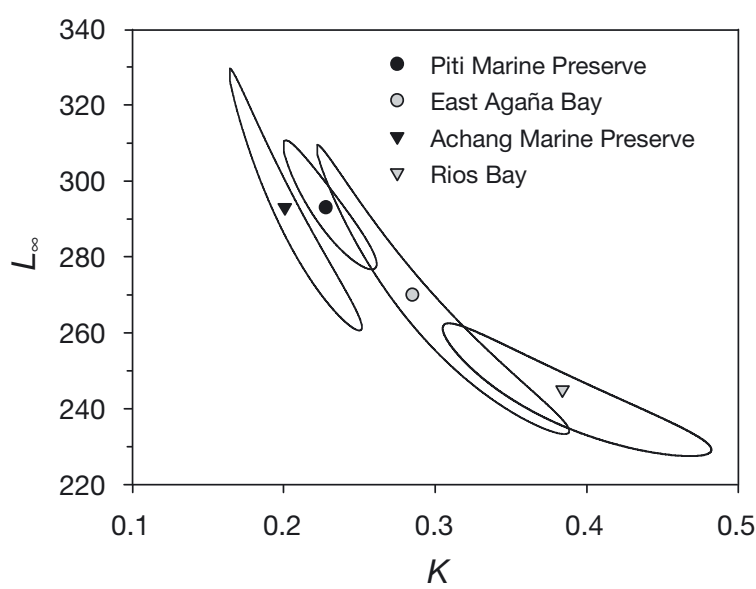

Fig. 7. Lethrinus harak. (A) Von Bertalanffy growth function (VBGF) fitted to size-at-age data for the 4 study sites. (B) Comparison of growth parameters among the 4 sites using bivariate 95\% confidence regions surrounding estimates of $K$ and $L_{\infty}$ 
Table 6. Lethrinus harak. (A) Fork length-at-age for ages 1 through 4 yr at the 4 study sites, means \pm SE. (B) Single-factor ANOVA tables comparing mean length-at-age between samples from protected versus unprotected sites for ages 1 through 4 yr. ${ }^{*} p<0.05$, ${ }^{* *} \mathrm{p}<0.001$. na $=$ not available

\begin{tabular}{|c|c|c|c|c|c|c|c|c|}
\hline (A) Site & $\mathrm{n}$ & Age 1 yr & n & $\begin{array}{l}\text { ork length-at } \\
\text { Age } 2 \text { yr }\end{array}$ & $\underset{n}{\operatorname{age}(\mathrm{mm})}$ & Age 3 yr & $\mathrm{n}$ & Age 4 yr \\
\hline Piti MPA & 3 & $123.7 \pm 9.1$ & 14 & $152.8 \pm 4.0$ & 10 & $199.3 \pm 2.2$ & 8 & $208.3 \pm 2.9$ \\
\hline East Agaña & 7 & $130.3 \pm 4.8$ & 25 & $174.3 \pm 3.6$ & 23 & $186.0 \pm 3.2$ & 6 & $210.5 \pm 5.3$ \\
\hline Achang MPA & 7 & $120.0 \pm 2.8$ & 10 & $138.8 \pm 3.2$ & 15 & $171.1 \pm 4.7$ & 16 & $197.8 \pm 4.2$ \\
\hline Rios Bay & 0 & na & 6 & $176.0 \pm 8.6$ & 9 & $197.7 \pm 3.2$ & 5 & $215.0 \pm 2.8$ \\
\hline \multicolumn{2}{|l|}{ (B) ANOVA } & \multicolumn{2}{|l|}{ Source of variation } & df & MS & $F$ & $\mathrm{p}$ & \\
\hline \multirow{2}{*}{\multicolumn{2}{|c|}{ Age 1 yr }} & Between groups & & 1 & 347.4 & \multirow[t]{2}{*}{2.876} & \multirow[t]{2}{*}{0.111} & \\
\hline & & Residual & & 15 & 120.8 & & & \\
\hline \multirow[t]{2}{*}{ Age 2 yr } & & Between groups & & 1 & 10369.5 & \multirow[t]{2}{*}{36.242} & \multirow[t]{2}{*}{$<0.001^{* *}$} & \\
\hline & & Residual & & 53 & 286.1 & & & \\
\hline \multirow[t]{2}{*}{ Age 3 yr } & & Between groups & & 1 & 678.4 & \multirow[t]{2}{*}{2.216} & \multirow[t]{2}{*}{0.142} & \\
\hline & & Residual & & 55 & 306.1 & & & \\
\hline \multirow[t]{2}{*}{ Age 4 yr } & & Between groups & & 1 & 955.3 & \multirow[t]{2}{*}{4.985} & \multirow[t]{2}{*}{$0.032^{*}$} & \\
\hline & & Residual & & 33 & 191.6 & & & \\
\hline
\end{tabular}

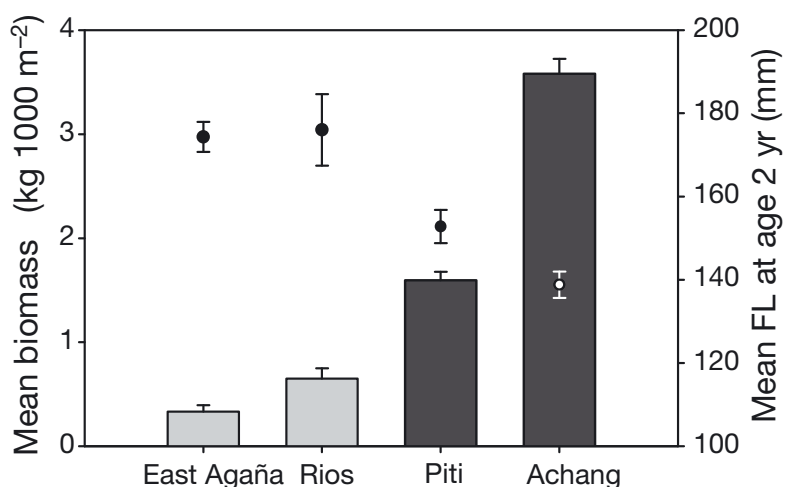

Fig. 8. Lethrinus harak. Biomass $1000 \mathrm{~m}^{-2}$ (bars) and fork length at age 2 yr (points) per site. Biomass estimated from stratified underwater visual surveys at each site. Mean values $\pm \mathrm{SE}$

levels, raising the length at first capture to 23 and 24.5 $\mathrm{cm}$ would increase SBR at both sites from $<3 \%$ to $25 \%$ and $48 \%$ of the unexploited value, respectively.

\section{DISCUSSION}

The need for effective management of Guam's inshore fisheries has been recognized for decades, as declines in catch per unit effort (CPUE) and increases in fishing pressure were evident as early as the 1970s (Hensley \& Sherwood 1993). A re-estimate of Guam's long-term catch and effort data revealed considerable under-reporting such that the total decline of the coral

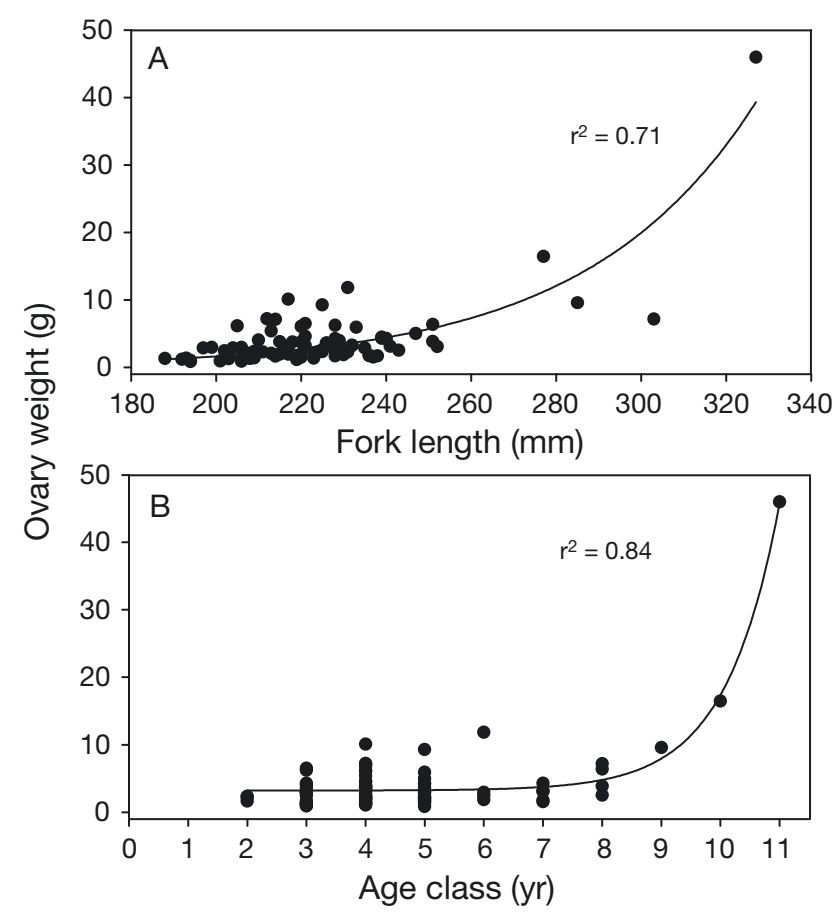

Fig. 9. Lethrinus harak. Ovary weights for mature, active females from all sites by (A) size and (B) age

reef fishery in the past 50 yr was closer to $86 \%$ (Zeller et al. 2007). The intention of the marine preserves, first established in 1997, was to reverse or slow these declining trends. While it is premature to suggest this goal has been achieved, the results of the present study demonstrate that a reduction in fishing pressure 

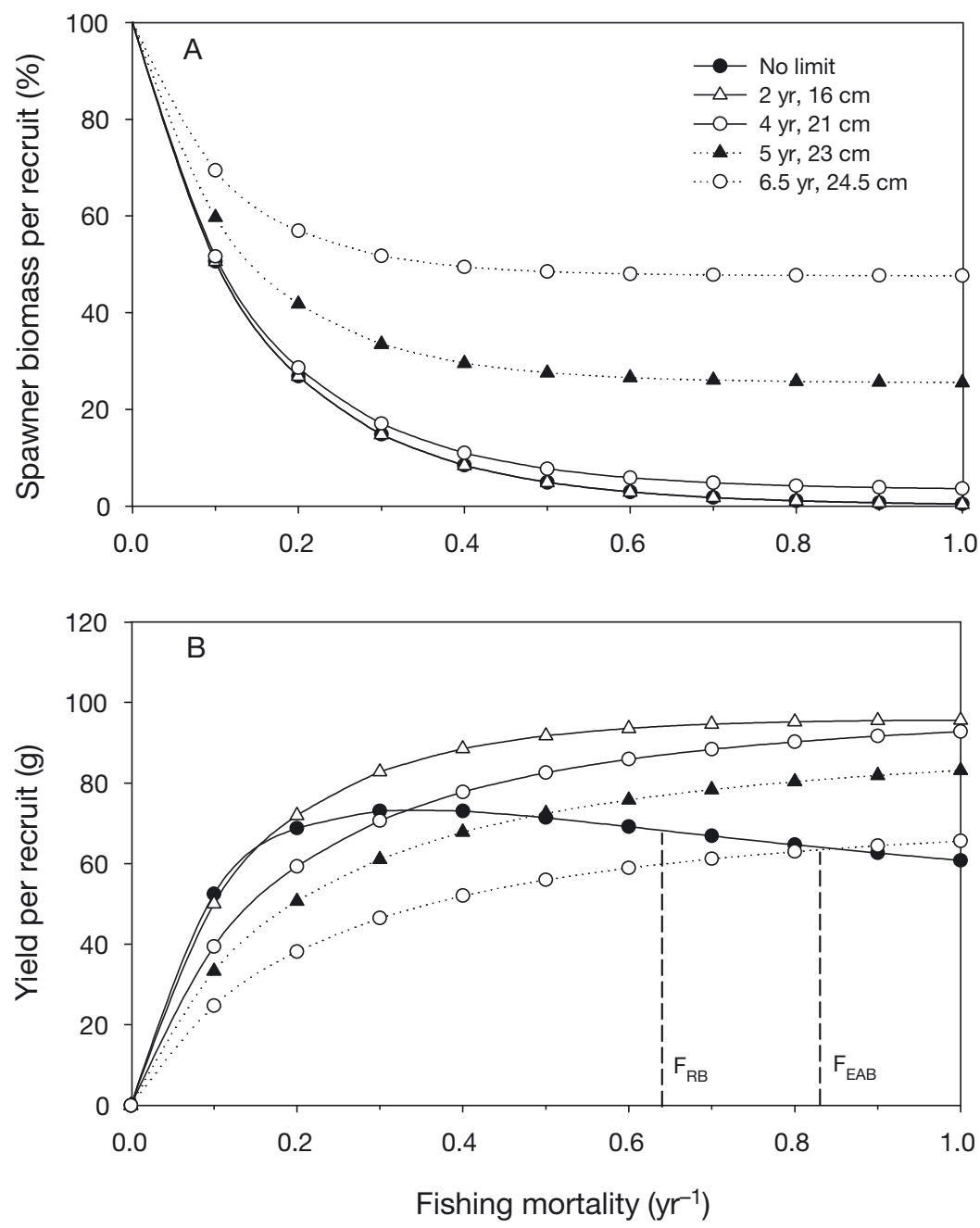

Fig. 10. Lethrinus harak. (A) Spawner biomass per recruit and (B) yield per recruit model trajectories for various ages and sizes at first-capture scenarios. Vertical dashed lines in (B) represent current scenarios regarding fishing mortality and entry into fishery for East Agaña Bay $\left(\mathrm{F}_{\mathrm{EAB}}\right)$ and Rios Bay $\left(\mathrm{F}_{\mathrm{RB}}\right)$

sites improved our estimates of the age structures and natural mortality. However, there are 2 important assumptions regarding the use of age-length keys to derive demographic information: (1) Ages are indeed accurate, as age determination errors can greatly affect the distribution of ages across a size class, especially in larger size classes where samples are typically rare (Cotter et al. 2004). (2) There is no regional variability in size-at-age across sampled locations, or that this variability has been adequately accounted for using multiple sparse age-length keys specific to locations to minimize error associated with regional differences in growth (Cotter 1998).

The catch curves indicated large differences in mortality rates between protected and unprotected sites. Comparison of demographic parameters derived from the LC and $\mathrm{RC}$ data suggest that the low sample size at Rios and the multiple sampling methods used to collect the RC data negatively influenced parameter estimates. The use of different sampling methods among sites likely had a strong influence on sitespecific $\mathrm{RC}$ data. At the one site where both methods were used (Piti), speared fish were on average slightly larger and older. However, using both methods in Piti appeared to be beneficial as it yielded similar size-frequency distributions between

has had a positive effect on the demography of Lethrinus harak through the significant accumulation of older individuals in certain areas.

The integration of fishery-independent and visual survey data is a novel approach for estimating sitespecific, age-based population parameters for coral reef fish. There are a number of advantages to using this method. For instance, it dramatically increases the sample size for demographic analysis through nonextraction, plus it provides better estimates of the youngest age classes often excluded by selective fishing. Reducing the level of destructive sampling necessary to obtain a suitable sample size (see Kritzer et al. 2001) has clear conservation benefits for monitoring fish populations in protected areas (Marsh \& Kenchington 2004). Increasing the sample size within study
UVC and RC data and, in turn, yielded similar parameter estimates between the methods. Hence, the importance of the LC method is highlighted because it corrected for such issues including the failure to sample larger (and presumably older) individuals from Achang, which resulted in a lower number of age classes in the RC catch curve. Data from the UVC indicate that larger individuals are considerably abundant in Achang, but a special permit to collect inside the MPA using hook and line, which was only valid for a few months and allowed a limited sample, made it difficult to collect fish from the oldest age classes.

Estimates of mortality were consistently lower in MPAs compared with unprotected sites. However, estimates of $M$ varied depending on the method. Pauly's (1980) equation provided estimates that often ex- 
ceeded Z calculated from the catch curves. This method often overestimates $M$ for slower growing tropical species (Ralston 1987) and was therefore not used in subsequent analyses. The simplistic derivation of the Hoenig (1983) equation can be a potential source of error (Grandcourt et al. 2006). However, it is typically considered a reliable and robust prediction of $M$, especially where larger and older individuals can be adequately sampled or maximum age in a truncated fishery can be predicted from other populations (Hart \& Russ 1996). Hence, the Hoenig (1983) estimate was used in this study to predict site-specific F and applied to the per-recruit analyses. Sampling from MPAs is also a useful and under-utilized method for estimating M (Bohnsack 1990, Russ et al. 1998), but may be less reliable in some instances for several reasons: MPAs rarely represent an unexploited population, but rather an unexploited segment of a population; the duration of protection afforded the MPA is often less than the longevity of the species studied (e.g. Lethrinus harak on Guam); and there are variable levels of poaching among MPAs and quantifying this impact is problematic.

Growth parameters in the present study were similar to previous estimates of Lethrinus harak growth from the northern GBR where $K$ and $L_{\infty}$ values were estimated at $0.313 \mathrm{yr}^{-1}$ and $285 \mathrm{~mm}$ FL resp. (Hilomen 1997). Estimates from Fiji, however, differed considerably, as $K$ and $L_{\infty}$ were resp. $0.9 \mathrm{yr}^{-1}$ and $285 \mathrm{~mm}$ TL ( 259 mm FL; Lasi 2003). Longevity ( $\left.t_{\max }\right)$ estimates, however, in all 3 studies were similar at 12, 13, and 15 yr for Fiji, Guam, and the GBR, respectively. The lack of small fish from Fiji (no samples <200 mm were aged) may have resulted in spurious parameter estimates as the VBGF is sensitive to both sample size and size or age distribution. To effectively estimate growth parameters it has been suggested that at least 7 to 10 individuals per age class be obtained (Kritzer et al. 2001). Problems regarding sample size and age class distribution were encountered in the present study particularly when fitting the site-specific growth curves. At the fished sites East Agaña and Rios, the UVC data revealed larger (and older) individuals were almost nonexistent. Therefore, the full growth potential of this species is unlikely to ever be reached at either of these sites due to overexploitation. For this reason, comparing the VBGF parameters among sites should be done with caution. In addition, no constraint for size-at-settlement was placed on the $y$ intercept in order to improve the best fit of the VBGF model. Constraining the VBGF generally enhances the precision of parameter estimates (Kritzer et al. 2001) by limiting the range of values possible, but for L. harak it caused a poor estimate of mean size-at-age using the VBGF model.
Using protected populations to examine densitydependent responses to fishing is a relatively new concept (Sanchez Lizaso et al. 2000). We found a negative relationship between mean size at age 2 and mean biomass, suggesting that growth of Lethrinus harak on Guam may be density-dependent. However, this effect was only vaguely consistent across all early age classes and therefore may represent or be confounded by sitespecific habitat differences or may vary among cohorts from year to year. An increased growth rate at lower densities is a response to the decrease in competition for limiting resources such as food and space (Jones 1991), competitive interactions that are reduced in exploited fish populations. For coral reef fish, densitydependent growth responses are more apparent in post-settlement and juvenile stages, particularly for non-exploited species (e.g. Jones 1987, Forrester 1990), but less so for adults. However, numerous examples of increased growth rates in exploited populations exist for temperate demersal fisheries (e.g. Rijnsdorp \& van Leeuwen 1992, Millner \& Whiting 1996, Harris \& McGovern 1997). Historical otolith back-calculation in North Sea plaice Pleuronectes platessa reveals both a reduction in growth rate following fishery closure in the 1940s and a subsequent increase after fishing resumed and populations declined (Rijnsdorp \& van Leeuwen 1992). Similarly, growth rates of North Sea sole Solea solea increased in the 1960s in conjunction with the expansion of beam trawling, which severely reduced population abundance (Millner \& Whiting 1996). For red porgy Pagrus pagrus in the South Atlantic Bight, however, growth increased after fishery expansion in the 1970 s, but later decreased as populations continued to decline, which was attributed to the selective nature of the fishery for targeting larger (and presumably faster-growing) individuals (Harris \& McGovern 1997). Beverton \& Holt (1957) emphasized not only the importance of population density to lifehistory traits, but also the importance of accounting for such density-dependent responses in fisheries management as failure to do so can severely affect yield estimates.

The significant differences in mean size at age 2 among sites open and closed to fishing suggest that density dependence may affect the growth of young fish. Nanami \& Yamada (2009) found that in Japan, agonistic behavior of Lethrinus harak occurred most frequently between similar-sized individuals, yet there was little overlap in the home ranges of these individuals. This suggests that $L$. harak are specifically territorial towards members of the same cohort rather than individuals in other life stages. Such intraspecific competition may be driven by ontogenetic shifts in dietary preference and possibly habitat. More detailed examination such as habitat-specific replication of sample 
sites, size-specific gut content analysis, and experimental manipulation of densities is necessary to draw definitive conclusions regarding site-specific growth effects.

Lethrinus harak is not particularly long-lived compared to most tropical lethrinids, lutjanids, and epinephelids. However, it is relatively slow-growing, indicating that exploitation rates should be conservative by maintaining $\mathrm{F}$ at equal to or below $\mathrm{M}$ (Coleman et al. 2000). Our estimates of site-specific exploitation rates show this is not the case, and that rates actually exceed these levels. In addition, per-recruit analyses suggest that the inclusion of minimum size limits for the species would be beneficial by rebuilding spawner biomass. This is only possible through effective enforcement and a concurrent outreach program. In fact, a minimum size limit of $23 \mathrm{~cm}$ would require very little trade-off in terms of YPR at low F values, but would yield an overwhelming increase in SBR for unprotected populations at all fishing intensities. However, a major obstacle to using size limits as a management tool is the frequency of unselective fishing methods (e.g. monofilament gill nets) in Guam's inshore fishery. An introduction of minimum size limits would offer little protection to under-sized fish without extensive regulations or an outright ban of these methods, an approach taken by the local fisheries agency in neighboring Saipan.

When making comparisons of age-based demography between sites open and closed to fishing, 2 assumptions are made regarding protection status and the movement patterns of reef fish (Ferreira \& Russ 1995): (1) no fishing occurs in the protected areas, and (2) fish movement across the preserve boundaries does not obscure the effects of protection on the age structure. While poaching is common in Guam's marine preserves, data from confiscated catches indicate that Lethrinus harak is rarely caught by illegal poaching (R. B. Tibbatts pers. comm.). This is probably due to the behavior of both the fish species and the poachers; most poaching is done by spearfishing at night to avoid detection and L. harak is not among the more commonly targeted species at night. As for the second assumption, Nanami \& Yamada (2009) showed that daytime home range size of $L$. harak is considerably small ( $\sim 3$ orders of magnitude smaller than the size of sites in the present study), and studies of home ranges in other reef fish species have revealed high site fidelity (Kramer \& Chapman 1999). Violation of these assumptions would yield a lack of difference in population structure between protected and unprotected reefs; however, this is not an issue in the present study because a consistent MPA effect was observed. Additionally, when interpreting differences in population structure between areas open and closed to fishing, it is important to realize that the variability observed (or lack thereof) is not only influenced by the reduction in fishing mortality, but also by the level of exploitation in unprotected sites, the duration of protection, and the degree of habitat variability among sites. Knowledge of these factors is important when evaluating the effectiveness of an MPA.

The present study has provided a rare insight into the performance of protected areas on Guam beyond simple measurements of abundance and biomass. Without the demographic data it would not have been possible to detect the accumulation of older individuals, the disproportionate contribution to reproductive output by older females, or the potential densitydependent effects on growth. Clearly, fishing pressure has significantly altered the size and age structure of the population in areas outside the preserves. We suggest that additional fisheries management should be attempted in areas open to fishing as the full extent of MPA benefits to fish populations is very dependent on the management regime outside these areas (Begg et al. 2005). We provide several options for managers, including the introduction of a minimum size limit, aimed at increasing SBR with little or no compromise to yield. On Saipan, the abundance of Lethrinus harak increased 4-fold (on average) from 2000 to 2005 (Starmer et al. 2008). The authors attribute this increase not only to the recent ban on certain fishing methods (SCUBA spearfishing and gill, drag, and surround nets) but also the presence of well-enforced MPAs. Introducing similar measures on Guam through gear or effort controls would require the cooperation of local fishermen, who must be consulted early in the review process. While these results provide a baseline, routine monitoring and assessment of L. harak and other reef fish species should be initiated in order to provide a comprehensive performance review of the existing preserves.

Acknowledgments. We thank S. Abellana, J. Cummings, A. Marshell, J. Miller, M. Priest, J. San Nicholas, K. San Nicholas, and K. Taylor for help in collection or processing of samples. We also thank A. Halford, A. Kerr, and K. Moots for comments on earlier versions of the manuscript. R. B. Tibbatts and the Division of Aquatic and Wildlife Resources assisted by providing fishery data and issuing permits to collect within marine preserves. S. Reilly assisted in gonad histology and interpretation and E. Matson provided his ultraviolet microscope. Comments from 4 anonymous reviewers aided considerably in the development of this manuscript. This study was conducted under the approval of the Animal Care and Use Committee, Office of Graduate School and Research, University of Guam. Funded in part by the US Fish and Wildlife's Federal Assistance in Sportfish Restoration Program to the Guam Department of Agriculture. 


\section{LITERATURE CITED}

Adams S, Mapstone BD, Russ GR, Davies CR (2000) Geographic variation in the sex ratio, sex specific size, and age structure, of Plectropomus leopardus (Serranidae) between reefs open and closed to fishing on the Great Barrier Reef. Can J Fish Aquat Sci 57:1448-1458

Begg GA, Mapstone BD, Williams AJ, Adams S, Davies CR, Lou DC (2005) Multivariate life-history indices of exploited coral reef fish populations used to measure the performance of no-take zones in a marine protected area. Can J Fish Aquat Sci 62:679-692

Berkeley SA, Chapman C, Sogard SM (2004) Maternal age as a determinant of larval growth and survival in a marine fish, Sebastes melanops. Ecology 85:1258-1264

Beverton RJH, Holt SJ (1957) On the dynamics of exploited fish populations. Fisheries Investment Series 2, Vol 19. UK Ministry of Agriculture and Fisheries, London

Bobko SJ, Berkeley SA (2004) Maturity, ovarian cycle, fecundity, and age-specific parturition of black rockfish (Sebastes melanops). Fish Bull 102:418-429

Bohnsack JA (1990) The potential of marine fishery reserves for reef fish management in the U.S. Southern Atlantic. NOAA Tech Rep NMFS-SEFC 261

> Buxton CD (1993) Life-history changes in exploited reef fishes on the east coast of South Africa. Environ Biol Fishes 36: $47-63$

Carpenter KE, Allen GR (1989) FAO species catalogue. Emperor fishes and large-eyed breams of the world (Family Lethrinidae). FAO Fish Synop 9:64-65

Chen Y, Jackson DA, Harvey HH (1992) A comparison of von Bertalanffy and polynomial functions in modeling fish growth data. Can J Fish Aquat Sci 49:1228-1235

Choat JH, Axe LM (1996) Growth and longevity in acanthurid fishes; an analysis of otolith increments. Mar Ecol Prog Ser 134:15-26

> Choat JH, Axe LM, Lou DC (1996) Growth and longevity in fishes of the family Scaridae. Mar Ecol Prog Ser 145:33-41

> Choat JH, Robertson DR, Ackerman JL, Posada JM (2003) An age-based demographic analysis of the Caribbean stoplight parrotfish Sparisoma viride. Mar Ecol Prog Ser 246: 265-277

Coleman FC, Koenig CC, Huntsman GR, Musick JA and others (2000) Long-lived reef fishes: the grouper-snapper complex. Fisheries 25:14-21

> Cotter AJR (1998) Method for estimating variability due to sampling of catches on a trawl survey. Can J Fish Aquat Sci 55:1607-1617

Cotter AJR, Burt L, Paxton CGM, Fernandez C, Buckland ST, Pan JX (2004) Are stock assessment methods too complicated? Fish Fish 5:235-254

Ebisawa A (2006) Reproductive and sexual characteristics in five Lethrinus species in waters off the Ryukyu Islands. Ichthyol Res 53:269-280

Ferreira B, Russ GR (1995) Population structure of the leopard coralgrouper, Plectropomus leopardus, on fished and unfished reefs off Townsville, Central Great Barrier Reef, Australia. Fish Bull 93:629-642

Forrester GE (1990) Factors influencing the juvenile demography of a coral reef fish population. Ecology 71: 1666-1681

Grandcourt E, Al Abdessalaam AT, Al Shamsi AT, Francis F (2006) Biology and assessment of the painted sweetlips (Diagramma pictum (Thunberg, 1792)) and the spangled emperor (Lethrinus nebulosus (Forsskal, 1775)) in the southern Arabian Gulf. Fish Bull 104:75-88

Gust N, Choat JH, Ackerman JL (2002) Demographic plastic- ity in tropical reef fishes. Mar Biol 140:1039-1051

Harris PJ, McGovern JC (1997) Changes in the life history of red porgy, Pagrus pagrus, from the southeastern United States, 1972-1994. Fish Bull 95:732-747

Hart AM, Russ GR (1996) Response of herbivorous fish to crown of thorns starfish Acanthaster planci outbreaks. III: Age, growth, mortality and maturity indices of Acanthurus nigrofuscus. Mar Ecol Prog Ser 136:25-35

Hensley RA, Sherwood TS (1993) An overview of Guam's inshore fisheries. Mar Fish Rev 55:129-138

Hilomen VV (1997) Inter- and intra-habitat movement patterns and population dynamics of small reef fishes of commercial and recreational significance. PhD thesis, James Cook University, Townsville

Hoenig JM (1983) Empirical use of longevity data to estimate mortality rates. Fish Bull 82:898-903

Johannes RE (1981) Words of the lagoon: fishing and marine lore in the Palau district of Micronesia. University of California Press, Berkeley, CA

> Jones GF (1987) Competitive interactions among adults and juveniles in a coral reef fish. Ecology 68:1534-1547

Jones GF (1991) Postrecruitment processes in the ecology of coral reef fish populations: a multifactorial perspective. In: Sale PF (ed) The ecology of fishes on coral reefs. Academic Press, San Diego, CA, p 601-635

Kimura DK (1980) Likelihood methods for the von Bertalanffy growth curve. Fish Bull 77:765-774

Kramer DL, Chapman MR (1999) Implications of fish home range size and relocation for marine reserve function. Environ Biol Fishes 55:65-79

Kritzer JP, Davies CR, Mapstone BD (2001) Characterizing fish populations: effects of sample size and population structure on the precision of demographic parameter estimates. Can J Fish Aquat Sci 58:1557-1568

Lasi F (2003) Age, growth, mortality rates and reproductive biology of three Fijian emperor fishes (Pisces: Lethrinidae): Lethrinus harak Forsskal, 1775, Lethrinus obsoletus, Forsskal, 1775 and Lethrinus atkinsoni, Seale, 1910. MS thesis, University of the South Pacific, Fiji

Manooch CS (1987) Age and growth of snappers and groupers. In: Polovina J, Ralston S (eds) Tropical snappers and groupers: biology and fisheries management. Westview Press, Boulder, CO, p 329-373

Marsh H, Kenchington R (2004) The role of ethics in experimental marine biology and ecology. J Exp Mar Biol Ecol 300:5-14

Millner RS, Whiting CL (1996) Long-term changes in growth and population abundance of sole in the North Sea from 1940 to the present. ICES J Mar Sci 53:1185-1195

Munro JL (1980) Stock assessment models: applicability and utility in tropical small-scale fisheries. In: Saila SB, Roedel PM (eds) Stock assessment for tropical small-scale fisheries. International Center for Marine Resources Development, University of Rhode Island, Kingston, RI, p 35-47

Nanami A, Yamada H (2009) Site fidelity, size, and spatial arrangement of daytime home range of thumbprint emperor Lethrinus harak (Lethrinidae). Fish Sci 75: 1109-1116

Pauly D (1980) On the interrelationships between natural mortality, growth parameters, and mean environmental temperature in 175 fish stocks. J Cons Int Explor Mer 39: 175-192

Pears RJ, Choat JH, Mapstone BD, Begg GA (2006) Demography of a large grouper, Epinephelus fuscoguttatus, from Australia's Great Barrier Reef: implications for fishery management. Mar Ecol Prog Ser 307:259-272

Polunin NVC (1990) Marine regulated areas: an expanded 
approach for the tropics. Resour Manage Optim 7:283-299

Ralston S (1987) Mortality rates of snappers and groupers. In: Polovina JJ, Ralston S (eds) Tropical snappers and groupers: biology and fisheries management. Westview Press, Boulder, CO, p 374-404

Ricker WE (1975) Computation and interpretation of biological statistics of fish populations. Bull Fish Res Board Can 191:1-382

Rijnsdorp AD, van Leeuwen PI (1992) Density-dependent and independent changes in somatic growth of female North Sea plaice Pleuronectes platessa between 1930 and 1985 as revealed by back-calculation of otoliths. Mar Ecol Prog Ser 88:19-32

Roberts CM, Bohnsack JA, Gell F, Hawkins JP, Goodridge R (2001) Effects of marine reserves on adjacent fisheries. Science 294:1920-1923

Roberts CM, Hawkins JP, Gell FR (2005) The role of marine reserves in achieving sustainable fisheries. Philos Trans $\mathrm{R}$ Soc Lond B Biol Sci 360:123-132

Russ GR (1991) Coral reef fisheries: effects and yields. In: Sale $\mathrm{PF}$ (ed) The ecology of fishes on coral reefs. Academic Press, San Diego, CA, p 601-635

Russ GR, Lou DC, Higgs JB, Ferreira BP (1998) Mortality rate of a cohort of the coral trout, Plectropomus leopardus, in zones of the Great Barrier Reef Marine Park closed to fishing. Mar Freshw Res 49:507-511

Sale PF (1978) Reef fishes and other vertebrates: a comparison of social structures. In: Reese ES, Lighter FJ (eds) Contrasts in behavior, adaptations in the aquatic and terrestrial environments. John Wiley \& Sons, New York, NY, p 313-346

Sale PF (1998) Appropriate spatial scales for studies of reeffish ecology. Aust J Ecol 23:202-208

Editorial responsibility: John Choat,

Townsville, Queensland, Australia
Sanchez Lizaso JL, Goni R, Reñones O, Garcia Charton JA and others (2000) Density dependence in marine protected populations: a review. Environ Conserv 27:144-158

Shapiro DY (1987) Differentiation and evolution of sex change in fishes. Bioscience 37:490-497

Sluka R, Sullivan KM (1996) The influence of habitat on the size distribution of groupers in the upper Florida Keys. Environ Biol Fishes 47:177-189

Sparre P, Ursin E, Venema SC (1989) Introduction to tropical fish stock assessment. Part 1. Manual. FAO Fish Tech Pap 306

Starmer J, Asher J, Castro F, Gochfeld D and others (2008) The state of coral reef ecosystems of the Commonwealth of the Northern Marianas Islands. In: Wadell JE, Clarke AM (eds) The state of coral reef ecosystems of the United States and Pacific Freely Associated States: 2008. NOAA Tech Memo NOS NCCOS 73. NOAA/NCCOS Center for Coastal Monitoring and Assessments Biogeography Team. Silver Spring, MD, p 437-463

Vaughan DS, Huntsman GR, Manooch CS, Rohde FC, Ulrich GF (1992) Population characteristics of the red porgy, Pagrus pagrus, stock off the Carolinas. Bull Mar Sci 50: $1-20$

West G (1990) Methods of assessing ovarian development in fishes: a review. Aust J Freshw Mar Res 41:199-222

Williams AJ, Davies CR, Mapstone BD, Russ GR (2003) Scales of spatial variation in demography of a large coral-reef fish-an exception to the typical model? Fish Bull 101: 673-683

Zeller D, Booth S, Davis G, Pauly D (2007) Re-estimation of small-scale fishery catches for U.S. flag-associated island areas in the western Pacific: the last 50 years. Fish Bull 105:266-277

Submitted: October 23, 2009; Accepted: May 25, 2010

Proofs received from author(s): July 25, 2010 